\title{
Who Needs the Experts? The Politics and Practices of Alternative Humanitarianism and Its Relationship to NGOs
}

\author{
Armine Ishkanian $^{1}$ (D) - Isabel Shutes ${ }^{2}$
}

Accepted: 13 April 2021/Published online: 7 May 2021

(C) The Author(s) 2021

\begin{abstract}
Drawing on fieldwork in Greece, we examine the politics and practices of autonomous volunteering in the context of the migration crisis. This involves individuals engaging in activities to support migrants through nonregistered, self-organized and self-governed groups that work independent from and in some cases, even in opposition to NGOs. We consider autonomous volunteering as a form of collective action and argue that it constitutes an alternative humanitarianism. While recent literature has sought to identify the rise of emergent practices of alternative humanitarianism in Europe, research has often overlooked how autonomous volunteers distinguish themselves from, relate to and collaborate with NGOs and conversely, how NGOs view and engage with them. We found that despite their critiques of NGOs and their determination to work independently, there were instances of cooperation between autonomous volunteers and NGOs. These interactions did not become substantive alliances, as the work of NGOs and autonomous volunteers continued to be disconnected from each other.
\end{abstract}

Keywords Social movements · NGOs · Volunteering · Humanitarianism $\cdot$ Migration

Armine Ishkanian

a.ishkanian@1se.ac.uk

1 Department of Social Policy and International Inequalities Institute, London School of Economics and Political Science (LSE), Centre Building, 4th Floor, London WC2A 2AE, UK

2 Department of Social Policy, London School of Economics and Political Science (LSE), London, UK

\section{Introduction}

Since the 1990s, Greece has been both a transit and destination country for migrants (Stevens, 2018), but when 850,000 people entered Greece in 2015 , the situation was termed a "refugee crisis" (European Commission, 2017) and a "global humanitarian crisis" (UN High Commissioner for Human Rights, 2014). As international humanitarian non-governmental organizations (NGOs) began their operations in Greece, they quickly discovered that, outside the institutionalized humanitarian system, a range of other actors had emerged, including large numbers of Greek solidarians and international volunteers, engaged in activities to support migrants through non-registered, selforganized and self-governed groups.

In the context of the so-called European migration crisis, an "unprecedented number" of people "operating outside the purview of the institutionalized regime of humanitarian care," stepped in to fill "the gaps left by the state and established NGOs" (Stavinoha and Ramakrishnan 2020: 165 emphasis in the original). This phenomenon has variously been called "volunteer humanitarianism" (Sandri, 2018), "civil humanitarianism" (Esperti, 2020) and "citizen aid" (Fechter \& Schwittay, 2019). Scholars have examined actors' motivations (Komenska 2017, Stavinoha and Ramakrishnan 2020), the forms and nature of their assistance (Bhimji, 2016; Esperti, 2020; Rozakou, 2016), and how they challenge traditional humanitarian practices, official migration, and border regimes (Ataç et al. 2016; Esperti, 2020; Haaland \& Wallevik, 2019; Sinatti, 2019).

While volunteers in the context of humanitarianism are hardly new (Baughan \& Fiori, 2015) and NGOs are the "best known facilitators of international volunteering" (Baillie Smith \& Laurie, 2011: 550), autonomous volunteering is distinct from traditional forms of volunteering, 
since these actors work autonomously from, in parallel to, and in some cases, even in opposition to NGOs. Autonomous volunteering is part of an emergent phenomenon in which "ordinary" people are initiating and engaging in "forms of aid and development... which are not orchestrated by large donors or aid agencies" (Fechter \& Schwittay, 2019:1769) and who are responding to local needs or shared interests rather than policy directives (McCabe et al 2010). These actors have been defined as volunteers, 'ordinary citizens' or new aid actors, who lack professional training in relief work, but take "independent initiative to resolve the needs of refugees" (Sandri, 2018: 77) and whose efforts "reflect resistance to the conventional aid architecture" (Haaland \& Wallevik, 2019: 1872). In the context of the migration crisis, there was diversity among autonomous volunteers; alongside "first-time untrained volunteers" there were "seasoned anarchists" who "espouse a borderless world" (Stavinoha and Ramakrishnan 2020: 169).

While recent literature has sought to analyze the development of these emergent practices of humanitarianism in Europe, there has been limited attention to the relationships between autonomous volunteers (AVs) and institutional humanitarian actors. AVs work in humanitarian spaces alongside NGOs, yet research has often overlooked how they distinguish themselves from, relate to and collaborate with NGOs (Martin \& Nolte, 2020) and conversely, how NGOs view and engage with them. In this article, drawing on fieldwork conducted in Greece in 2017-2018, with follow-up interviews in 2019, we examine the politics and practices of AVs and ask to what extent it involves collaboration with or resistance to NGOs, and vice versa. We consider autonomous volunteering as a form of collective action. Drawing on social movement theory (Amenta \& Polletta, 2019; Jasper, 2011; Pleyers, 2010; van Stekelenburg \& Klandermans, 2013), we explore how identity, agency, values, and emotions inform AVs' actions and shape their approaches to assisting migrants and relations with NGOs and the relationship between what Fassin calls "morals" (i.e., principles) and "politics" (i.e., actions) in humanitarianism (Fassin, 2012: 8).

We found that while AVs were motivated by empathy and solidarity, which are also motivations shared by international volunteers working in NGOs (Baillie Smith \& Laurie, 2011, MacNeela, 2008, Meneghini, 2016, Rehberg, 2005), unlike traditional volunteers, AVs criticize NGOs and choose to work independently. We argue that AVs' practices and politics constitute an alternative or alt-humanitarianism, which is centered on making visible and meeting the needs of all migrants not just those who were classified as 'refugees' through the governance of asylum and adopting approaches that prioritize dignity, respect, and solidarity, rather than expediency. In some, albeit not all, instances AVs also view their efforts as a form of antisystemic resistance. Despite their critiques of NGOs and determination to work independently, there were instances of cooperation between AVs and NGOs. Cooperation emerged when there were personal connections and shared values between $\mathrm{AVs}$ and NGOs. Cooperation did not emerge when NGOs faced organizational constraints or if AVs were ideologically opposed to working with NGOs and adhered to strict principles of autonomy and anti-systemic resistance. Finally, even in the instances of cooperation, these interactions did not become substantive alliances, as NGOs and AVs continued to work disconnected from each other, thus limiting the possibilities for more coordinated assistance to migrants and for achieving wider structural changes to official migration policies and practices.

Our research on $\mathrm{AVs}$ and the politics and practices of alt-humanitarianism contributes to the growing literature on non-institutional, alternative humanitarian responses to the migration crisis in Europe (Esperti, 2020; Haaland \& Wallevik, 2019; Rozakou, 2017; Sandri, 2018; Sinatti, 2019; Theodossopoulos, 2016) and to wider conceptual debates and theorizing in social movement and NGO studies on NGO-activist alliances (Banks et al., 2015, Bebbington et al., 2008, Duyvenda and Jasper, 2015, Feenstra, 2018, Lewis, 2019, Martin \& Nolte, 2020, Pearce, 2010, Zihinoğlu, 2019; Glasius and Ishkanian 2015, Ishkanian and Ali 2018).

We differentiate between two types of AVs, Greek solidarians and international volunteers, and explore the differences between them. We use the term 'solidarian' to refer to Greeks supporting migrants in an unpaid capacity. In Greece, the term "volunteer" is contested and seen as "being too close to the official humanitarian apparatus" (Stavinoha and Ramakrishnan, 2020: 170). The term "solidarian," which was initially confined to anarchist circles, is now commonly used locally to refer to individuals providing unpaid support to migrants (Rozakou, 2016). Solidarian was not a term used by international volunteers who traveled to Greece from countries in Europe and North America to provide assistance through autonomous groups; these individuals referred to themselves as 'volunteers' and that is the term we use in the article. For ease of reference, we use 'autonomous volunteers' as an umbrella term, which includes both Greek solidarians and international volunteers, but acknowledge differences where appropriate.

We begin with a discussion of critical approaches to humanitarianism, including the recent literature on alternative forms of humanitarian action in the context of the European migration crisis. We highlight the need to consider how contentious but also solidaristic politics may underpin those actions, as well as potential alliances with 
NGOs alongside resistance. We then turn to examine the findings of research interviews with AVs and NGOs in the context of the migration crisis, exploring AVs' motivations and how these shaped their actions and interactions with migrants and NGOs in the humanitarian spaces in Greece.

\section{Civil Society and Humanitarianism}

Since the early twentieth century, the discourse of Western humanitarianism has been built on "a belief in the equal and essential worth of every human being" (Baughan \& Fiori, 2015: S129) and humanitarianism has often been "treated as a symbol of what is good about the world" (Barnett and Weiss 2011: 6). Following high profile failures of humanitarianism in Rwanda and Haiti, there were increasing calls that professionalization was a "necessary endeavor" and that "professional and "business-like", approaches would enhance the accountability and effectiveness of humanitarian NGOs (James, 2016: 185). While recognizing the heterogeneity of humanitarian NGOs and that professionalization may improve their technical capacity and accountability (James, 2016), many question the wider impact of humanitarian NGOs. Some argue that humanitarian NGOs are failing to articulate political solutions (De Waal, 1997; Calhoun, 2008; Ticktin, 2014) and that current practices of professionalized humanitarianism reproduce hierarchies and perpetuate "bioinequalities" that determine "the sort of life people may or may not live" (Fassin, 2009: 49) and whose lives are seen as surplus (Li, 2010).

In the context of the migration crisis, NGOs, alongside the European Union (EU), national governments, and UN agencies, were seen by some as inadequately responding to the needs of migrants and their inaction was seen as worsening the suffering (Cuttitta, 2018; Davies et al., 2017). NGOs have also been criticized of being "co-opted" by national governments and the EU (Fekete, 2018: 74) and at times, of being complicit in state-driven processes of securitization and control (Pecoud 2015). By choosing to work outside of NGOs, AVs are seen as providing an "alternative to the "humanitarian machine'," which is populated by NGOs and UN agencies (Sandri, 2018: 66). The work of AVs in the migration crisis has been described as a form of activism (Sinatti, 2019) and AVs are described as engaging in contentious politics (Ataç et al., 2016), that seek to subvert the "twin humanitarian logics of depoliticization and dehumanization" (Stavinoha and Ramakrishnan, 2020: 166) and to challenge the "European deterrence-oriented governmental policies at the borders" (Esperti, 2020:437).

At the same time, studies of local responses in Greece to the migration crisis, to which our work contributes and builds, describe responses to assisting migrants as forms of solidarity (allileggî̀) (Papataxiarchis, 2016; Rozakou, 2017; Theodossopoulos, 2016). In examining local understandings and uses of the term solidarity, scholars argue that since the early 2010 s, a "highly politicized model" of solidarity acquired "a new relevance" in Greece (Theodossopolous, 2020: xx) and has come to represent a wider array of progressive, anti-systemic action (Rakopoulos 2016). There are low levels of trust in professionalized NGOs in Greece (Papataxiarchis, 2016; Simiti, 2017) and solidarians work in groups that stand outside and at times in direct opposition to NGOs. While Greek civil society is considered "weak" because of the small number of professionalized, formally registered NGOs, in contrast, there is the "vibrant, informal, non-institutionalized, often nonregistered Greek civil society sector," which expanded in relation to the dual contexts of the austerity and migration crises in Greece (Kalogeraki, 2020:784). Bagavos and Kourachanis (2021) argue that the refugee crisis led to the "bifurcation of civil society" between NGOs and the "informal solidarity movement" as these two sets of actors "mobilized in different ways to support refugees" (2021: 6). They maintain that there is "fragmentation" between these "two poles of civil society," due to their perceptions of welfare and in particular the "philosophy" of grassroots solidarity initiatives (GSIs), which adopt "an egalitarian approach" to migrants viewing them as "equal members" rather than beneficiaries of aid (Bagavos \& Kourachanis, 2021: 9). While Bagavos and Kourachanis (2021) examine the differential approaches of NGOs and GSIs, they do not consider how these two sets of actors viewed or interacted with each other, as we do in this article.

In developing our conceptual and empirical understandings of alternative humanitarianism, the above literature points to the need to consider the dynamics of alternative volunteering, including international volunteers and Greek solidarians, in terms of a politics of resistance to institutionalized NGO operations, but also one of solidarity with migrants. However, to what extent do AVs collaborate with established NGOs and what is the potential but also limits to those relationships? Social movement theories provide a useful conceptual framework for examining how "creativity and agency, culture and meaning, emotion and morality" (Jasper 2010: 970) inform and shape collective action and social relations, including cooperation and alliance building with NGOs (Amenta \& Polletta, 2019, Duyvendak and Jasper, 2015, Gamson, 1991, van Stekelenburg \& Klandermans, 2013). In examining alliances between social movements and other actors, scholars have argued that the agency, strategic choices, and power differences between actors determine why and how cooperation emerges (Duyvendak and Jasper, 2015: Jasper 2010). While considering how the need for resources can drive 
cooperation (Rucht, 2004), they acknowledge how activists' fears of co-option, de-politicization, and loss of values hinders it (Pleyers, 2010; Glasius and Ishkanian 2015).

Some argue that if NGOs want to "make a difference" and have real impact, they should "think consciously of themselves as part of a social movement" (Bebbington et al., 2008: 32), build alliances with grassroots groups (Pearce, 2010) and "return to politics in the broadest sense, and retreat from the idea that transformation is simply the aggregate of technical interventions" (Banks et al., 2015: 715). While such arguments have merit, we should not ignore the agency of AVs or assume they want to work with NGOs (Glasius and Ishkanian 2015, Ishkanian and Ali 2018). Moreover, critical studies of autonomous or "informal" volunteering (Whittaker et al., 2015), raise important questions about NGOs' interest in or desire for cooperation, noting how NGOs sometimes view such actors "as a nuisance or liability" (Whittaker et al., 2015: 359). Others note that NGOs, which face strict accountability requirements, cannot afford to work with untrained volunteers (Freedman, 2018; McAllum, 2018) when despite the best intentions, AVs' "ignorance of the consequences and priorities in emergency relief may lead to more negative consequences" (Komenska 2017: 147). In addition to NGOs' concerns about the risks of working with AVs, some argue that NGOs' foregrounding of organizational interests and the "power dynamics, culture, financing and incentive structures erect barriers ...to more constructive and fruitful engagement between those within and outside the current formal [humanitarian] system" (Bennett, 2016: 5). We consider the factors that enable or hinder cooperation between AVs and NGOs and the points of tension and conflict.

Fechter and Schwittay contend, that while grassroots efforts "can become acts of protest and resistance," this does not mean they entirely "avoid the entrenched hierarchies and inequalities of power" (2019: 1776). Thus, there is a need to both focus on the potential of alt-humanitarianism, but also acknowledge its limitations including "frequent lack in resources, efficiency and influence on broader power relations" (Arampatzi, 2018: 57) as well as incidences of "volunteer tourism" (Papataxiarchis, 2016: 8).

In the following sections, we examine the politics and practice of alt- humanitarianism in the context of the migration crisis, with regard to the perceptions and experiences of different types of $\mathrm{AVs}$ as well as those working within national and INGOs operating in Greece. The former includes two types of AVs (Greek solidarians and international volunteers, coming to Greece from other European and North American countries). There is a large literature on the meanings of solidarity in general and in the context of collective action with migrants (Bauder and Juffs 2020, Della Porta, 2018), however, it remains an "unclear" concept (Bauder and Juffs 2020: 47). Bauder and Juffs' typology of solidarity in relation to migration includes "recognitive solidarity," which they define as encompassing "autonomist" practices and other "volunteer contributions" including cooking and collective action with and for migrants (Bauder and Juffs 2020: 56). With reference to the identities and principles referred to by $\mathrm{AVs}$ in our research, the aim in this article is to not to assume that all actors are driven by a sense of solidarity, but rather to examine whether and how informal actors viewed their work as a form of solidarity, and how understandings of solidarity shaped their assistance to migrants and engagement with NGOs. Equally, we consider how AVs defined themselves and their actions in relation to alternative principles.

\section{Methods}

The bulk of the research for this article was carried out in 2017 and 2018 in Athens and Lesvos, with some follow-up interviews in 2019 in London; however, it is also informed by fieldwork on solidarity activism in Athens conducted by one of the researchers in 2013-2014 (Glasius and Ishkanian 2015; Ishkanian and Glasius 2018).

An initial mapping exercise identified different types of civil society actors, including representatives of international NGOs, Greek NGOs, and UN agencies as well as Greek solidarians, and international volunteers that had been involved in supporting migrants on the islands and in mainland Greece. A purposive sampling approach was adopted to select actors from across the different groupings. In-depth interviews were carried out with 28 individuals including, nine representatives working for international NGOs; four representatives working for domestic NGOs; eight international volunteers who had traveled to Greece from countries in Europe and North America during or after 2015; five Greek solidarians, and two interviews with people working within United Nations High Commissioner for Refugees (UNHCR) operations in Greece and the Reception and Identification Service operated by the Greek government.

Interviews, which lasted between 45 and $90 \mathrm{~min}$, were carried out by the authors or the Greek research assistant involved in the data collection, allowing interviewees to reflect on the development of activities and changes since the crisis peaked in 2015. Interviews were conducted in English or Greek, but all transcripts were translated into English, coded, and analyzed around four broad categories: motivations; practices; understandings of and discourses around certain concepts (e.g., solidarity); and views of and 
relationships to other types of actors in the humanitarian space. These categories were chosen in line with the aims of the research project and were reflected in the questionnaire design. We chose these categories with the aim of understanding the motivations, understandings, and practices of different actors working in humanitarian spaces, and their relationships to each other as well as the State. We explore civil society actors' views and engagement with the State in a separate article (Shutes and Ishkanian 2021). All names have been anonymized.

Although our interviewees would use both the terms "refugee" and "migrant," in the article we use the term "migrant" to refer to all people (including refugees) whose mobility into Europe through Greece was severely restricted by state and inter-state immigration controls, recognizing that the categorization of migrants/refugees is central to those controls (Allen et al., 2018).

\section{MOTIVATIONS}

In this section, we consider the motivating logics that informed the work of AVs and consider how these are shaped by social norms and cultural understandings, as well as by individual agency and emotions (Amenta \& Polletta, 2019; Jasper, 2011; Malkki, 2015; van Stekelenburg \& Klandermans, 2013). We discuss how both empathy as well as more political understandings of solidarity motivated AVs and explore the shared understandings, but also the divergent viewpoints.

\section{Empathy}

The act of witnessing migrants' suffering on the news or in person was a key motivation and the attendant emotions of anger, pity, and indignation prompted people into action. For instance, Claudio, from Europe, said, “...when Aylan [sic] Kurdi died it was my birth...I have a friend who also saw these images and we said, 'We must go to help.", Matthew, from Europe, also described feeling a "moral obligation to play an active role in it and not just watch it on TV."

Similarly, Elizabeth, from North America, spoke of becoming angry when seeing images of suffering, adding, "I wanted to go into Syria, like everyone else, and to be an aid worker." Unable to go to Syria, Elizabeth, stayed in Greece to "help from here." Solidarians described how locals from diverse social backgrounds provided assistance to migrants who were living in the streets or squares in their towns and cities as a way of "defending their values" (Giannis), describing the widespread outpouring of support as a "grassroots movement" (Xanthe) and an expression of shared humanity (Zena). Beyond being motivated by empathy, solidarians also spoke of their actions as expressions of solidarity.

\section{Solidarity and Resistance}

Scholars have noted how solidarity actions in Greece are informed by a "highly politicized model" of solidarity (Papataxiarchis, 2016: 8) which first emerged in response to the austerity crisis, but was later expanded to migrants (Rozakou, 2016)(Ishkanian and Glasius 2018). Several Greek interviewees explained that their actions were informed by their understandings of what it means to be a good person in their society and their experiences during the austerity crisis. Some argued that by working in solidarity with migrants, there was the possibility to regain one's sense of "pride" (Sofia) and "basic humanity, their dignity" (Vasos) which had suffered under the harsh austerity regime. Nikola explained the connection between her work with migrants and her earlier involvement in austerity related solidarity initiatives saying, "the positive part of the Greek [austerity] crisis was that we started to talk again about solidarity...It is very political, solidarity." Meanwhile Xanthe, said, "You can't be someone who believes in social justice, in people's right to have equal opportunities and see this situation and not get involved...You have to be a pig [not to get involved]." For Darius, solidarity meant seeing the struggles of others as being connected to your own:

The Greek people have stood very much with refugees...They bring food and this has been very important. They do this not because they feel sorry, but because they feel they are connected somehow with these people. Because they are facing a real war in Syria and in Greece, we are facing an economic war.

Giannis explained how solidarity was a form of resistance saying: "We help refugees as an act of solidarity to those coming but also as an act of resistance to what was happening...resistance to the failing state."

While social norms and cultural understandings of solidarity informed the work of Greek solidarians, several international volunteers were wary of the concept of solidarity. Elizabeth, said, "Solidarity? It's bullshit. Sorry, but this my level of disgust for it." Marianne, from North America described solidarity as "activist jargon" and Abi, from Europe was also disinclined to describe her actions as an act of solidarity, saying,

I am reluctant to use that term [solidarity] in discussing my motivations even though I could see elements of it there. But how could I possibly empathize with the situations these people are going 
through? I can build something with people, but I don't think I could understand. I don't think I could feel empathy or solidarity with people when there's such a gulf in experience.

While Abi, Elizabeth, and Marianne, viewed their work as a form of assistance that was independent from NGOs, they did not view it as a form of solidarity. However, some international volunteers also spoke of how their experiences in Greece led them and others they knew, to become more politicized and to engage in "activism," even if they did not describe their efforts as a form of solidarity. Tabitha from Europe said:

There are a lot of volunteers who come and help, who wouldn't necessarily identify themselves as 'activists'...some of those people then become more political. They start to ask about deportations, saying, 'can we organize a demonstration against this or that'... 'Can we move from the humanitarian to the political a bit more?'

\section{Perceptions of NGO Failure}

While some AVs had specialist knowledge or skills in teaching, legal work, or search and rescue, not all did and the commitment to helping and value driven work was considered by many a far more essential factor than professional knowledge or expertise. For instance, Matthew, who had initially worked as a volunteer in Calais and came to Greece in 2016, said, "One thing Calais did was to build into our collective consciousness the idea that you might not be an expert or have a Master's in like Gender and Development or something, and you can potentially go and start a project." He added, "The reason why our operations in Calais sprang into being and the reason why all the projects are happening in Greece is because of failure of the EU and large NGOs." Elizabeth, criticized "established" NGOs saying,

When I was in [camp], I was doing a lot of things ... But the NGO [staff] would scream a lot at the kids...I would be watching the volunteers in terrible weather, doing things, and not acting like that. Then you had [the NGO staff] acting like monsters...it started this idea in my mind that this is the time that there is going to be a true challenge to established NGOs.

Similarly, Nikola questioned the effectiveness of NGOs:

I thought that all these big NGOs with the big funds and experience in dealing with crises, that they would make a difference. But it took months and huge resources, to do very minimal things... it was very disappointing.
In this section, we considered how empathy, understandings of solidarity as well as perceptions of NGOs' failures informed AVs' actions in seeking to assist migrants, but also why they did so independent of NGOs. We now turn to consider how these understandings shaped the politics and practices of alt-humanitarianism of AVs.

\section{THE POLITICS AND PRACTICES OF ALT-HUMANITARIANISM}

Regardless of motivating logic, AVs defined their actions in terms of the importance of aiding migrants on the basis of need. They were involved in a range of activities including search and rescue; distribution of food; medical services; educational activities for children and language classes; day centers providing a variety of services; and legal assistance with asylum processes and access to social rights, such as housing for registered asylum seekers. Some had been involved in providing services within camps, while others worked solely outside of camps, including establishing alternative accommodation for migrants on unused public and privately owned sites. AVs were not only filling the "gaps left by the state and established NGOs" (Stavinoha and Ramakrishnan 2020: 165), but on a more strategic level, AVs were committed to the practice of alt-humanitarianism which was centered on making visible the needs of migrants, questioning the sovereignty of the State and EU to decide who is deserving of assistance, and providing assistance in a manner that prioritized dignity, respect and solidarity, over expediency.

The majority of migrants in Greece came from Syria, Afghanistan and Iraq, but there were also migrants from Pakistan, Eritrea, and Somalia (UNHCR, 2016). In the past decade, Greece has increasingly become a site for the inequalities of mobility in terms of the differentiation of the deserving/undeserving refugee and migrant, as country of origin and nationality determine how people are categorized and what support they receive. For example, while Syrians were recognized through official channels as "refugees," the majority of migrants from South Asia and Africa were deemed "economic migrants," irrespective of individual circumstances, and thus ineligible for EU funded support. An "economic migrant," according to the European Commission, is a person "... who leaves their country of origin purely for economic reasons that are not in any way related to the refugee definition [as defined under international law], in order to seek material improvements in their livelihood" (European Commission, 2019). This distinction became significant when the EU stipulated that European funding was solely intended to "...fund emergency support operations addressing the needs of these refugees" (European Commission, 2017) [emphasis 
added]. These distinctions have been critiqued as reinforcing and perpetuating "bio-inequalities" which determine "the sort of life people may or may not live" (Fassin, 2009: 49) and delineating who is deserving of saving and whose lives are seen as surplus (Li, 2010). Unlike the NGOs which received EU funding, AVs subverted such classifications, aiding migrants regardless of country of origin or potential legal status. For instance, Darius argued,

There is this thing of who deserves which kind of treatment and access to rights...they built different types of camps according to which nationality you are, what kind of people you are and there are different kinds of conditions. The camps for Syrian refugees are a little better, then less better for the Afghans, and the worst ones were for the Sub Saharan refugees.

Darius described how his group was "trying to create an example of an alternative to the camps" and which challenged the Greek State's and EU's practice of categorizing people as 'refugees' or 'non-refugees' which determined who was deserving of aid and the type of aid received. Elizabeth spoke of the importance of maintaining independence, saying: "We don't take money from anyone, we don't make deals... if we get harassed by the police, fine. It is better than watching people die knowing you could have done something."

As noted earlier, AVs criticized some NGOs working within the EU funded system of humanitarian assistance for failing to adequately support migrants. Large NGOs in particular were seen as disconnected from migrants:

The bigger NGOs are much further removed from the refugees and their realities than we are...for us refugees are the center of the work, what they need, what they want is our starting point, but I don't see that starting point reflected in the bigger organisations' work, it's much more top down (Tabitha).

Key examples of alt-humanitarianism were the alternative accommodations sites for migrants created by solidarians. During our fieldwork in 2017, we visited two alternative sites. Site A, which was based in Lesvos founded on the principles of solidarity, empowerment and active participation and run as an open accommodation space allowing migrants free movement. It was framed as a place where migrants would be treated with dignity, love, safety, and respect.

Another example was Site B in Athens, which was also was created as a space of safety and dignity for migrants, however, it had a more political orientation and sought to function as a center of struggle against racism, borders, and social exclusion. It prided itself on providing housing for migrants in Athens without any funding from formal institutions or NGOs.

Both alternative accommodation sites had been created by solidarians, but international volunteers subsequently also become involved in the work of both alternative sites and migrants participated in the daily operations and decision-making. While both sites were centered on creating alternatives to traditional humanitarianism, Site A had relations with NGOs and on occasion, received support from them, meanwhile Site B embraced a more stringent political position explicitly framing itself as being in opposition to the dominant model of managing migration and was highly critical of NGOs and what it called, NGOization.

While acknowledging the positive aspects of alt-humanitarianism as practiced by AVs in Greece, including adopting migrant-centric and emancipatory approaches, we also recognize the limitations and challenges (Arampatzi, 2018; Fechter \& Schwittay, 2019), including the lack of impact on the structures and systems of official migration and border regimes. Respondents also noted the difficulties in achieving systemic change (Nikola, Darius) and other challenges including problems of accountability (Marianne), sustainability (Carla, Tabitha, Elizabeth), and voluntourism (Abi, Zena). These are important questions for future researchers, but assessing the operational impact of alt-humanitarianism was not the focus of our research.

We now turn to examine relations between AVs and NGOs.

\section{AUTONOMOUS VOLUNTEERS AND NGOS}

In this section, we examine the relationship between NGOs and AVs and consider the factors which enabled, or hindered, cooperation (Bagavos \& Kourachanis, 2021, Duyvendak and Jasper, 2015, Jasper 2010, Feenstra, 2018, Rucht, 2004). We discuss how personal connections and shared values were key elements in enabling cooperation, however personal connections and shared values alone were insufficient. In instances where NGO staff had concerns around reputational risk and accountability to donors or there was a hierarchical organizational culture that did not permit operational field autonomy, cooperation did not emerge, even where personal connections existed, as staff were reluctant or unable to engage with AVs. Focusing on the agency of AVs, we discuss how cooperation emerged when AVs embraced a pragmatic approach and sought trainings or material support from NGOs, but it did not emerge in instances of AVs whose work was informed by a strict adherence to ideological principles. 


\section{Personal Connections and Shared Values}

Apart from one interviewee, all INGO staff we interviewed were Greek nationals, some of whom had returned to Greece from postings abroad to work during the crisis. Many of these Greek INGO employees (Angeliki, Christos, Nemea, Evanthe, Ioanna, Sofia, Vasos) said they supported solidarity initiatives in their private capacity, however, a smaller number (Evanthe, Sofia, Vasos) also engaged with and provided support through their formal roles. For example, Vasos, who worked for an INGO and who supported solidarity initiatives by providing material assistance through his NGO, said "Many of these grassroots volunteers see big NGOs as part of the problem, because we are part of the system an extra effort is needed from our side to gain trust... It takes some guts, but it is worthwhile." Evanthe, who worked for a different INGO said,

Big NGOs would have the attitude of we're not going to deal with these guys or we are professionals, they are volunteers; we know what we do, they don't. At the same time volunteers would accuse us of being paid and there was this constant debate wherever you would go that 'I am a volunteer, I am not getting paid for what I am doing, so you have to listen to me'. There was this hostility and then gradually, there would come mutual respect and some NGOs would start doing in-kind donations to them, and the volunteers would request trainings.

She described how the INGO she worked for donated supplies and provided trainings to volunteers. Evanthe acknowledged that she could do this because the organizational culture (Bennett, 2016) allowed field staff to have operational autonomy, including whether and how to work with AVs. Evanthe, Sofia and Vasos recognized that other INGOs did not give field staff such autonomy, adding that even some of their colleagues in their respective INGO headquarters did not consider cooperation with AVs as worthwhile or in some cases, appropriate. Vasos said, "there was discussion internally...there were offices that felt really very uncomfortable." Vasos, and Evanthe, maintained that personal relationships enabled cooperation with AVs, but without field level operational autonomy, this would not have been possible. AVs who received support from INGOs, spoke of personal relations and shared values as important factors. Xanthe explained: "They were allies not because of their posts or their institutional roles but because they could act as human beings within these roles." Similarly, Nikola, whose group received support from an INGO explained this cooperation occurred because "we had a good connection."

\section{Ascendancy of Organizational Interests}

Other NGO professionals, the majority of whom were Greek nationals, had personal connections with AVs but cited concerns around reputational risk, the need to protect organizational interests, and to maintain accountability to donors (Freedman, 2018, Komenska 2017) as reasons for not engaging with AVs. For example, Andreas, who worked for an INGO said,

The question was how to balance making use of your expertise but at the same time collaborate with all these grassroots organizations and individuals who don't necessarily understand humanitarian work and principles. Good will is important, but you need protocols and procedures so you don't actually harm the people you are supposed to be serving... Obviously, there was a level of suspicion between international agencies and local civil societies and grassroots movements. We tried to be very inclusive and participatory, but many INGOs, at least ourselves, refused to work with them.

NGOs are accountable to their donors, they are regulated by states, and in 2003 the Humanitarian Accountability Partnership was created which is “...dedicated to building a system of self-regulation based upon quality management and accountability principles" (Prevention Web, 2019). AVs are not bound by the aforementioned code of conduct and until 2017, was there no oversight from the Greek government of their activities. Several NGO respondents argued that they avoided working with AVs due to accountability concerns. Khloe, who worked for an INGO said, "we are under so much monitoring, evaluation, and audits." Similarly, Irini who worked for a domestic NGO, insisted that their accountability to their donors was the determining factor in choosing not to engage with AVs.

Gregory, who worked for a local NGO, argued there was concern around reputational risk due to the highly politicized and "disruptive" approach of some solidarians. He differentiated between international volunteers and Greek solidarians saying:

I think that volunteers are the ones that usually accept the fact that you also need organised structures, like NGOs, to do somethings. Solidarity movements usually have more political ideologies...they think we need to disrupt the system...[but] we are not here to fight the police.

Gregory acknowledged that solidarians were "critical about what NGOs are, where our funding comes from," but added that these were "non-issues" and he was content to work with international volunteers while not engaging with solidarians. 


\section{The Agency of Autonomous Volunteers}

Some AVs, including Elizabeth, Nikola, Xanthe, Marianne, Carla, Tabitha and Zena, embraced pragmatic stances and discussed how their groups had received assistance, whether in the form of trainings or material goods, from NGOs. For instance, Nikola, who viewed solidarity as being very important and a "political choice," nonetheless argued for a pragmatic approach, saying,

...we were very political, and would distinguish everything saying, 'we don't want humanitarianism, it's not for us'... I realized at one point that you cannot distinguish. You cannot say, 'I am here for the political part of the work and I see the person hungry and don't do anything' ... it is a human reaction, you cannot put a distinction - like I am not giving food because that is humanitarianism... you cannot have people without clothes and you are speaking about general things, like changing policies in Europe and safe passage, open borders.

Solidarians who had stricter ideological stances would not cooperate with NGOs under any circumstances. As Giannis said: "Each time we discussed contacting an institution or NGO, people were completely opposed." Such skepticism and lack of trust in NGOs was widely shared in Greek society (Bagavos \& Kourachanis, 2021; Kalogeraki, 2020; Simiti, 2017) and limited cooperation between solidarians and NGOs. At times, the reluctance to engage escalated into more direct forms of action against NGOs. For instance, arriving at the offices of one local NGO, we found the message below spray-painted on the door, which the NGO claimed was done by a group of solidarians.

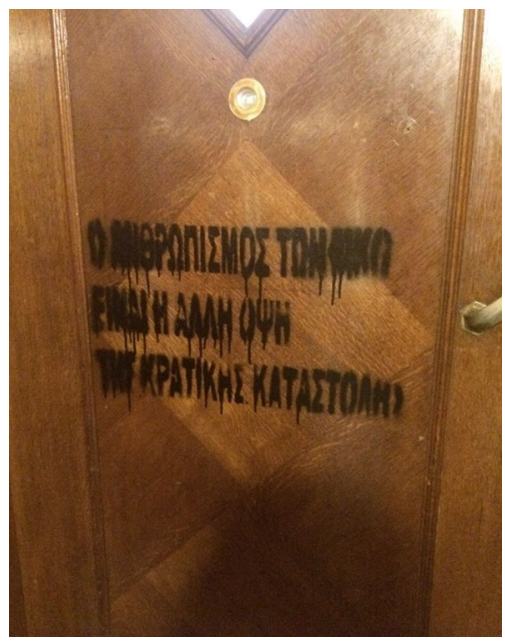

It reads: "The humanitarianism of NGOs is the other side of the State's repression" (Photo by Armine Ishkanian, Athens, June 2017) and it encapsulates, as we found, many solidarians' negative perceptions, lack of trust in, and refusal to cooperate with NGOs. An employee at the NGO which had been targeted, discussed how the graffiti was not an isolated incident and discussed how the NGO was frequently targeted. When asked who was critical of their actions, she replied, "Some of them were solidarians, some refugees, some from Golden Dawn ${ }^{1}$...We are criticised by so many people."

\section{Conclusion}

In this article, we examined the politics and practices of AVs in the migration crisis in Greece who work outside of, in parallel to, and at times in opposition to professional NGOs. We argued that AVs' practices and politics constitute an alternative humanitarianism, that is centered on making visible and meeting the needs of all migrants not just those who were classified as 'refugees' and adopting more migrant-centric approaches that prioritized dignity, respect, and solidarity, rather than expediency, and at times involved anti-systemic resistance.

Given the critiques of the apolitical stances of humanitarian INGOs (Calhoun, 2008, De Waal, 1997, Ticktin, 2014), their perceived role in reproducing or maintaining "bio-inequalities" (Fassin, 2009) and the assumption that informal actors can work with greater independence (Haaland \& Wallevik, 2019; Sandri, 2018), we considered the relationship between "morals" (i.e., principles) and "politics" (i.e., actions) in humanitarianism (Fassin, 2012: 8). We recognized the potential of alt-humanitarianism in creating more emancipatory and migrant-centered approaches, but also recognized its limitations in achieving structural changes to national and EU migration and asylum policies.

In considering the relationship between AVs and NGOs and the possibilities for alliances, we found that while most AVs were critical of the perceived inaction or ineffectiveness of NGOs, there were instances of cooperation. We maintain that individual agency affected actions and that personal connections and shared values were important factors in enabling cooperation. However, these alone were insufficient, indicating the importance of considering the tensions between individual agency and structural/organizational factors (Duyvendak and Jasper, 2015; Jasper, 2011; Pleyers, 2010) and how NGOs' organizational priorities and procedures shaped the actions of NGOs (Bennett, 2016; Whittaker et al., 2015). For NGO staff, organizational factors, including field level operational autonomy and concerns with reputation and accountability to donors determined whether they cooperated with AVs. The agency of AVs also shaped cooperation (Duyvendak and Jasper, 2015; Jasper, 2011), in

\footnotetext{
${ }^{1}$ Golden Dawn is a far right, anti-immigrant political party.
} 
that while some viewed engaging with NGOs as a pragmatic step to access trainings and resources, others, namely solidarians, avoided working with NGOs, due to ideological principles. While there were instances of cooperation between some AVs and NGOs, these were isolated incidents and did not evolve into substantive alliances. NGOs and AVs continued to work independently and disconnected from each other thus limiting the potential of more coordinated approaches to aiding migrants and for achieving structural changes to official migration policies and practices. Our findings on how personal connections, agency and organizational culture and priorities shape NGO-AVs cooperation, contributes to the conceptual debates and theorizing around why and under what circumstances NGOs cooperate with activists in humanitarian spaces (Lewis, 2019; Martin \& Nolte, 2020, Whittaker et al., 2015) and what cooperation can achieve (Bennett, 2016).

Future research should examine how the practices and politics of autonomous volunteering change over time and whether such initiatives are tackling the problems they identify in institutional humanitarianism or reproducing the same "power inequalities" (Fechter \& Schwittay, 2019: 1772). This will allow us to have a more nuanced understanding of diverse civil society responses to humanitarian crises, the possibilities for and impact of relationships between NGOs and AVs in humanitarian spaces, and the challenges all civil society actors face in achieving systemic change in the context of humanitarianism.

Acknowledgments We gratefully acknowledge and thank Christina Psarra and the research participants for their contribution to this research, and thank Konstantina Davaki and the two reviewers for their helpful comments on this paper.

Funding The authors did not receive support from any organization for the submitted work. The authors have no relevant financial or nonfinancial interests to disclose.

Open Access This article is licensed under a Creative Commons Attribution 4.0 International License, which permits use, sharing, adaptation, distribution and reproduction in any medium or format, as long as you give appropriate credit to the original author(s) and the source, provide a link to the Creative Commons licence, and indicate if changes were made. The images or other third party material in this article are included in the article's Creative Commons licence, unless indicated otherwise in a credit line to the material. If material is not included in the article's Creative Commons licence and your intended use is not permitted by statutory regulation or exceeds the permitted use, you will need to obtain permission directly from the copyright holder. To view a copy of this licence, visit http://creativecommons. org/licenses/by/4.0/.

\section{References}

Allen, W., Anderson, B., \& Van Hear, N. (2018). Who counts in crises? the new geopolitics of international migration and refugee governance. Geopolitics, 23(1), 217-243
Amenta, E., \& Polletta, F. (2019). The cultural impact of social movements. Annual Review of Sociology, 45, 279-299

Arampatzi, A. (2018). Constructing solidarity as resistive and creative agency in austerity Greece. Comparative European Politics, 16(1), 50-66

Ataç, I., Rygiel, K., \& Stierl, M. (2016). The contentious politics of refugee and migrant protest and solidarity movements: remaking citizenship from the margins. Citizenship Studies, 20(5), 527-544

Bagavos, C., \& Kourachanis, N. (2021). Civil society organizations and labour market integration for refugees and asylum seekers in Greece. VOLUNTAS: International Journal of Voluntary and Nonprofit Organizations. https://doi.org/10.1007/s11266-02100333-x

Baillie Smith, M., \& Laurie, N. (2011). International volunteering and development: global citizenship and neoliberal professionalisation today. Transactions of the Institute of British Geographers, 36(4), 545-559

Banks, N., Hulme, D., \& Edwards, E. (2015). NGOs, states, and donors revisited: still too close for comfort. World Development, 66, 717-718

Baughan, E., \& Fiori, J. (2015). Save the children, the humanitarian project, and the politics of solidarity: Reviving dorothy buxton's vision. Disasters, 39(2), S129-S145

Bebbington, A., Hickey, S., \& Mitlin, D. (2008). Can NGOs make a difference: The challenge of development alternatives. Zed.

Bennett, C. (2016) Time to let go: Remaking humanitarianism for the modern era. ODI https://www.odi.org/sites/odi.org.uk/files/ resource-documents/10422.pdf

Bhimji, F. (2016). Visibilities and the politics of space: refugee activism in Berlin. Journal of Immigrant and Refugee Studies, 14(4), 432-450

Calhoun, C. (2008). The imperative to reduce suffering: charity, progress, and emergencies in the field of humanitarian action. In M. Barnett \& T. G. Weiss (Eds.), Humanitarianism in question: Politics, power, ethic. (pp. 73-97). Cornell University Press.

Cuttitta, P. (2018). Repoliticization through search and rescue? humanitarian NGOs and migration management in the central mediterranean. Geopolitics, 23(3), 632-660

Davies, T., Isakjee, A., \& Dhesi, S. (2017). violent inaction: the necropolitical experience of refugees in Europe. Antipode, 49(5), 1263-1284

Della Porta, D. (Ed.) (2018). Solidarity mobilizations in the refugee crisis, palgrave studies in European political sociology.

De Waal, A. (1997). Famine crimes: Politics and the disaster relief industry in Africa, Oxford, James Currey

Duyvendak, J. W., \& Jasper, J.M. (2015). Players and arenas: The interactive dynamics of protest. Amsterdam University Press.

European Commission. (2017). Greece: Response to the refugee crisis-ECHO factsheet http://ec.europa.eu/echo/files/aid/coun tries/factsheets/greece_en.pdf . Accessed 18 September 2017.

European Commission. (2019). 'Economic Migrant' definition: https://ec.europa.eu/home-affairs/what-we-do/networks/eur opean_migration_network/glossary_search/economic-migrant_ en Accessed 16 January 2020.

Esperti, M. (2020). Rescuing migrants in the central mediterranean: The emergence of a new civil humanitarianism at the maritime border. American Behavioral Scientist, 64(4), 436-455

Fassin, D. (2009). Another politics of life is possible. Theory, Culture and Society, 26(5), 44-60

Fassin, D. (2012). Humanitarian Reason: A moral history of the present. University of California Press.

Fechter, A.-M., \& Schwittay, A. (2019). Citizen aid: grassroots interventions in development and humanitarianism. Third World Quarterly, 40(10), 1769-1780 
Feenstra, R. A. (2018). Blurring the lines between civil society, volunteering, and social movements a reflection on redrawing boundaries inspired by the Spanish case. VOLUNTAS: International Journal of Voluntary and Nonprofit Organizations, 29(6), $1202-1215$

Fekete, L. (2018). Migrants, borders and the criminalisation of solidarity in the EU. Race \& Class, 59(4), 65-83

Freedman, J. (2018). Amateur humanitarianism, social solidarity and 'volunteer tourism' in the EU refugee 'crisis.' In A. Ahmad \& J. Smith (Eds.), Humanitarian action and ethics.London: Zed Books.

Glasius, M., Ishkanian, A. (2015). Surreptitious Symbiosis: Engagement between activists and NGOs. VOLUNTAS: International Journal of Voluntary and Nonprofit Organizations, 26(6):2620-2644

Gamson, W. (1991). Commitment and agency in social movements. Sociological Forum, 6, 27-50

Haaland, H., \& Wallevik, H. (2019). Beyond crisis management? The role of citizen initiatives for global solidarity in humanitarian aid: the case of lesvos. Third World Quarterly, 40(10), 1896-1883

Ishkanian, A., Ali, I.S. (2018). From consensus to dissensus: The politics of anti-austerity activism in London and its relationship to voluntary organizations. Journal of Civil Society, 14(1), 1-19

Ishkanian, A., Glasius, M. (2018). Resisting neoliberalism? Movements against austerity and for democracy in Cairo, Athens and London. Critical Social Policy, 38(3), 527-546

James, E. (2016). The professional humanitarian and the downsides of professionalisation. Disasters, 40(20), 185-206

Jasper, J. M. (2010). Social Movement Theory Today: Toward a Theory of Action? Sociology Compass, 4(11), 965-976

Jasper, J. M. (2011). Emotions and social movements: twenty years of theory and research. Annual Review of Sociology, 37, 285-303

Kalogeraki, S. (2020). A mixed method approach on greek civil society organizations supporting migrants during the refugee crisis. Journal of International Migration and Integration., 21(3), 781-806

Lewis, D. (2019). Humanitarianism, civil society and the Rohingya refugee crisis in Bangladesh. Third World Quarterly, 40(10), 1884-1902

Li, T. M. (2010). To make live or let die? Rural dispossession and the protection of surplus populations. Antipode, 41(s1), 66-93

MacNeela, P. (2008). The give and take of volunteering: motives, benefits, and personal connections among Irish volunteers. VOLUNTAS: International Journal of Voluntary and Nonprofit Organizations, 19, 125-139

Malkki, L. H. (2015). The need to help: the domestic arts of international humanitarianism. NC: Duke University Press

Martin, E. C., \& Nolte, I. M. (2020). Might less accountability be more? INGO-volunteer relationships in the European refugee response. Public Management Review, 22(3), 408-431

McAllum, K. (2018). Committing to refugee resettlement volunteering: attaching, detaching and displacing organizational ties. Human Relations, 71(7), 951-972

McCabe, A. J. Phillimore, and L. Mayblin. (2010). 'Below the radar' activities and organisations in the third sector: A summary review of the literature. Third sector research centre. https:// www.birmingham.ac.uk/Documents/college-social-sciences/ social-policy/tsrc/working-papers/working-paper-29.pdf

Meneghini, A. M. (2016). A meaningful break in a flat life: the Motivations behind overseas volunteering. Nonprofit and Voluntary Sector Quarterly, 45(6), 1214-1233

Papataxiarchis, E. (2016). Being "there": At the front line of the 'European refugee crisis'-part 1. Anthropology Today, 32(3), $5-9$
Pearce, J. (2010). Is social change fundable? NGOs and theories and practices of social change. Development in Practice, 20(6), $621-635$

Pleyers, G. (2010). Alter-Globalization: Becoming Actors in the Global Age. Polity Press.

Prevention WEB. 2019. Humanitarian Accountability Partnership: https://www.preventionweb.net/organizations/2545 Accessed 15 March 2020

Rakopoulos, T. (2016). Solidarity: the egalitarian tensions of a bridgeconcept. Social Anthropology, 24(2), 142-151

Rehberg, W. (2005). Altruistic individualists: Motivations for international volunteering among young adults in Switzerland. VOLUNTAS: International Journal of Voluntary and Nonprofit Organizations, 16(2), 109-122

Rozakou, K. (2016). Socialities of solidarity: revisiting the gift taboo in times of crises. Social Anthropology, 24(2), 185-199

Rozakou, K. (2017). \#Humanitarianism: The Blurred Boundaries of Humanitarianism in Greece. Ethofoor, 29(2), 99-104

Rucht, D. (2004). Movement allies, adversaries and third parties. In D. Snow, S. A. Soule, \& H. Kriesi (Eds.), The Blackwell companion to social movements. Oxford: Blackwell Publishing.

Sandri, E. (2018). "Volunteer humanitarianism": volunteers and humanitarian aid in the jungle refugee camp of Calais. Journal of Ethnic and Migration Studies, 44(1), 65-80

Shutes, I., Ishkanian, A. (2021). Transnational welfare within and beyond the nation-state: civil society responses to the migration crisis in Greece. Journal of Ethnic and Migration Studies. https://doi.org/10.1080/1369183X.2021.1892479

Simiti, M. (2017). Civil society and the economy: Greek civil society during the economic crisis. Journal of Civil Society, 13(4), $357-373$

Sinatti, G. (2019). Humanitarianism as politics: Civil support initiatives for migrants in milan's hub. Social Inclusion., 7(2), $139-148$

Stavinoha, L. and Ramakrishnan, K. (2020). Beyond humanitarian logics: Volunteer-refugee encounters in Chios and Paris. Humanity, 11(2), 164-186

Stevens, D. (2018). Greece as "transit country": the role of law and policy. Journal of Ethnic and Migration Studies, online first.

Theodossopoulos, D. (2016). Philanthropy or solidarity? Ethical dilemmas about humanitarianism in crisis-afflicted Greece. Social Anthropology, 24(2), 167-184

Ticktin, M. (2014). Transnational humanitarianism. Annual Review of Anthropology, 43, 273-289

United Nations Office of the High Commissioner for Human Rights. (2014). Italy/Migrants: "A humanitarian crisis must have a global humanitarian response" - UN rights expert. Available: https://www.ohchr.org/EN/NewsEvents/Pages/DisplayNews. aspx?NewsID=15386 Accessed 15 July 2019.

UNHCR (2016). Refugees \& migrants sea arrivals in europe: https:// data2.unhcr.org/en/documents/download/49921 Accessed 16 January 2020.

Van Stekelenburg, J., \& Klandermans, B. (2013). The social psychology of protest. Current Sociology, 61, 886-905

Whittaker, J., Mclennan, B., \& Handmer, J. (2015). A review of informal volunteerism in emergencies and disasters: Definition, opportunities, and challenges. International Journal of Disaster Risk Reduction, 13, 2015

Zihnioğlu, Ö. (2019). The Prospects of civic alliance: new civic activists acting together with civil society organizations. VOLUNTAS: International Journal of Voluntary and Nonprofit Organizations, 30, 289-299

Publisher's Note Springer Nature remains neutral with regard to jurisdictional claims in published maps and institutional affiliations. 